\title{
2-Phenylnaphthyridin-4-one Derivative LYF-11 Inhibits Interleukin-6-mediated Epithelial-to- Mesenchymal Transition via the Inhibition of JAK2/STAT3 Signaling Pathway in MCF-7 Cells
}

\author{
LIANG-CHIH LIU ${ }^{1,2}$, YAO-CHUNG WU ${ }^{1,2}$, SHENG-CHU KUO ${ }^{3}$, \\ CHI-TANG $\mathrm{HO}^{4}$, TZONG-DER WAY ${ }^{5,6,7}$ and SHOU-TUNG $\mathrm{CHEN}^{8}$ \\ ${ }^{1}$ Department of Surgery, China Medical University Hospital, Taichung, Taiwan, R.O.C.; \\ ${ }^{2}$ Department of Medicine, College of Medicine, ${ }^{3}$ School of Pharmacy, College of Pharmacy, \\ ${ }^{5}$ Department of Biological Science and Technology, College of Biopharmaceutical and Food Sciences, \\ China Medical University, Taichung, Taiwan, R.O.C.; \\ ${ }^{4}$ Department of Food Science, Rutgers University, New Brunswick, NJ, U.S.A.; \\ ${ }^{6}$ Department of Health and Nutrition Biotechnology, Asia University, Taichung, Taiwan, R.O.C.; \\ ${ }^{7}$ Institute of Biochemistry, National Chung Hsing University, Taichung, Taiwan, R.O.C.; \\ ${ }^{8}$ Comprehensive Breast Cancer Center, Changhua Christian Hospital, Changhua, Taiwan, R.O.C.
}

\begin{abstract}
Background/Aim: Breast tumor interleukin-6 (IL-6) level increases with tumor grade, and elevated serum IL-6 correlates with poor survival in patients with breast cancer. Epithelial-mesenchymal transition (EMT) phenotypes are associated with enhanced metastasis and unfavorable clinical outcome in breast cancer. Therefore, we examined whether IL-6 induced EMT phenotype characterized in breast cancer cells. Materials and Methods: MCF-7 cells treated with different concentrations $(10-50 \mathrm{ng} / \mathrm{ml})$ of $\mathrm{IL}-6$ for 24 and $48 \mathrm{~h}$. Western blotting, flow cytometry, and cell migration assay were used to test whether IL-6 promoted tumorinitiating ability in MCF-7 cells. Results: In this study, we found that the induction of EMT by IL-6 resulted in the acquisition of mesenchymal traits and the increase of tumorinitiating ability in MCF-7 cells. Moreover, we found that 2-phenylnaphthy-ridin-4-one derivatives were able to repress
\end{abstract}

Correspondence to: Shou-Tung Chen, MD, Ph.D., Comprehensive Breast Cancer Center, Changhua Christian Hospital, 135 Nanhsiao Street, Changhua 50006, Taiwan, R.O.C. Tel: +886 47238595, e-mail: shouting_Chen@cch.org.tw and Tzong-Der Way, Ph.D., Department of Biological Science and Technology, College of Biopharmaceutical and Food Sciences, China Medical University, Taichung, Taiwan No.91 Hsueh-Shih Road, Taichung, Taiwan 40402, R.O.C. Tel: +886 4-22053366 ext: 2509, Fax: +886 4-2203 1075, e-mail: tdway@mail.cmu.edu.tw

Key Words: IL-6, EMT, breast cancer, tumor-initiating ability, JAK2/STAT3.
IL-6 induced EMT phenotype and tumor-initiating ability. Among these deriveratives, LYF-11 possessed the most potential inhibitory activity. LYF-11 effectively inhibited IL-6induced EMT phenotype and tumor-initiating ability via the inhibition of Janus kinase 2 (JAK2)/signal transducer and activator of transcription 3 (STAT3) signaling pathway. Conclusion: Our results suggest a connection between IL-6 receptor activity and EMT phenotype, and tumor-initiating ability. Moreover, LYF-11 is a potential compound for breast cancer therapy by targeting JAK2/STAT3 signaling pathway.

Breast cancer is the most commonly diagnosed cancer in women, and the second leading cause of death among women (1). Recent evidence suggests that breast cancer is a disease caused by tumor-initiating cells (2). The tumor-initiating cells have four key characteristics namely increased self-renewal capacity, enhanced differentiation capacity, increased tumorigenicity, and resistance to chemotherapy (3-5).

Recent findings illustrated a direct link between the epithelial-mesenchymal transition (EMT) and the gain of tumor-initiating properties (6). In order to form macroscopic metastases, the EMT enables cancer cell dissemination and cells may acquire a self-renewal capability (7). After transition, migratory mesenchymal cells are endowed with mesenchymal markers, such as the overexpression of vimentin and $\mathrm{N}$-cadherin (with concomitant loss of $\mathrm{E}$ cadherin). During this process, various transcription factors, including SNAIL, SLUG, TWIST, ZEB1, and ZEB2, are implicated in the control of EMT (8). 
<smiles>COc1cccc(-c2cc(=O)c3cc(C)cnc3[nH]2)c1</smiles>

LYF-5<smiles>Cc1ccnc2[nH]c(-c3ccccc3F)cc(=O)c12</smiles>

LYF-11<smiles>COc1cccc(-c2cc(=O)c3c(C)ccnc3[nH]2)c1</smiles>

LYF-17

Figure 1. Chemical structures of LYF-5, LYF-11, and LYF-17.

An inflammatory microenvironment is believed to promote tumor metastasis by facilitating EMT. A growing body of evidence demonstrates that inflammatory factors are closely linked to cancer and inflammation (9). Inflammatory factors, such as interleukin-6 (IL-6), IL-1 $\beta$, and tumor necrosis factor- $\alpha$ (TNF- $\alpha$ ), are key constituents of an inflammatory microenvironment. Human breast tumors exhibit increased IL-6 expression compared with matched healthy breast tissue (10). As increasing level of IL-6 correlates with advanced tumor grade, increased metastatic propensity, and poor survival $(11,12)$. Moreover, recent studies have elucidated that IL-6 is capable of inducing EMT and expanding the tumor-initiating cell population in breast cancer cells (13-15).

In an inflammatory microenvironment, IL-6 is secreted into the extracellular matrix by inflammatory cells. Upon binding of IL-6 to the IL-6 receptor (IL-6R), IL-6R associates with glycoprotein 130 (GP130), which triggers signal transducer and activator of transcription 3 (STAT3) phosphorylation by Janus kinases (JAKs) (16). The phosphorylated STAT3 then form homo- or heterodimers that translocate to the cell nucleus where they act as transcription activators. The transcription activators bind to cognate DNA sequences, and promote transcription of their target genes, including E-cadherin, SNAIL, and TWIST, and modulate fundamental cellular processes $(17,18)$.

The 2-phenyl-4-quinolones and related synthetic quinolone derivatives have been reported to exhibit promising cytotoxicity against a broad spectrum of human cancer cell lines and inhibited platelet aggregation (19). Moreover, 2-phenyl-4quinolones derivatives inhibited tubulin polymerization by binding to tubulin at the colchicine-binding site and acted as anti-mitotic agents (20,21). Recently, 2-(2-fluorophenyl)-6,7methylenedioxoquinolin-4-one (CHM-1) was shown to inhibit tubulin polymerization and showed a cytotoxic effect on glioblastoma multiforme, ovarian cancer, osteogenic sarcoma, leukemia, and hepatocellular carcinoma cell lines (22-26).
Structurally, 2-phenyl-1,8-naphthyridin-4-ones (PNTOs) can be considered isosteres of 2-phenyl-4-quinolones. Since incorporation of an additional nitrogen atom into the quinolone at the 8-position does not change the basic 2-phenyl-4quinolone skeleton, PNTOs could be predicted to have similar biological activity to 2-phenyl-4-quinolones. In our previous study, a series of substituted PNTOs were evaluated for their relative potency as anticancer drugs; most showed potent cytotoxic and antitubulin activty (35).

\section{Materials and Methods}

Chemicals and reagents. PNTOs LYF-5, LYF-11, and LYF-17 were synthesized in our laboratory (Figure 1). Primary monoclonal antibodies against JAK2 [rabbit \#3230), phospho-JAK2Tyr1007/1008 [rabbit \#3776), phospho-STAT3Ser727 (mouse \#9136), STAT3 (rabbit \#12640), and E-cadherin (rabbit \#3195) were purchased from Cell Signaling Technology (Beverly, MA, USA). Primary antibody against vimentin was purchased from Abcam Inc. (Cambridge, MA, USA). Primary antibody against $\beta$-actin was purchased from Sigma Chemical Co. (St. Louis, MO, USA). Secondary antibodies horseradish peroxidase-conjugated goat antimouse IgG, and goat anti-rabbit IgG were obtained from Millipore (Billerica, MA, USA). (-)-epigallocatechin-3-gallate (EGCG), IL-6, and 4,6-diamidino-2-phenylindole (DAPI) were obtained from Sigma Chemical Co.. Cell culture materials were obtained from Invitrogen (Burlington, ON, Canada).

Cell lines and cell cultures. MCF-7 cells were purchased from the American Type Culture Collection (Manassas, VA, USA). MCF-7 cells were cultured in Dulbecco's modified Eagle's medium (DMEM) containing 10\% fetal bovine serum (FBS) and 1\% penicillin-streptomycin. Cells were grown in a humidified incubator at $37^{\circ} \mathrm{C}$ under $5 \% \mathrm{CO}_{2}$ in air. Cell culture materials were obtained from Invitrogen (Burlington, Ontario, Canada).

Western blotting. MCF-7 cells $\left(2 \times 10^{6}\right)$ were seeded onto a $10-\mathrm{cm}$ dish, incubated for $24 \mathrm{~h}$, and pretreated with dimethyl sulfoxide (DMSO; control) or increasing LYF-5, LYF-11, and LYF-17 concentrations (25, $50 \mathrm{nM})$ for $2 \mathrm{~h}$ prior to IL-6 stimulation $(50 \mu \mathrm{g} / \mathrm{ml})$ for $24 \mathrm{~h}$. Protein extraction from cultured cells as previously described (27). Cells were 
harvested and the protein fraction was ext was performed racted by adding $50 \mu \mathrm{l}$ of gold lysis buffer [50 mM Tris- $\mathrm{HCl}(\mathrm{pH} 7.4), 1 \mathrm{mM}$ phenylmethylsulfonyl fluoride, $1 \mathrm{mM} \mathrm{NaF}, 1 \% \mathrm{NP}-40,150 \mathrm{mM} \mathrm{NaCl}$, $1 \mathrm{mM}$ EGTA, and $10 \mathrm{mg} / \mathrm{ml}$ leupeptin) to the cell pellets. Lysate protein was measured by Lowry protein assay (Bio-Rad Laboratories, Berkeley, CA, USA). Protein extract $(50 \mu \mathrm{g})$ was then loaded onto sodium dodecyl sulphate-polyacrylamide gels, the proteins were separated by electrophoresis, and the separated proteins were transferred to polyvinylidene fluoride transfer membrane (BioTrace, Bridgend, UK). Signals from the E-cadherin, vimentin, JAK2, phospho-JAK2, STAT3, phospho-STAT3 and $\beta$-actin antibodies were detected with an ECL chemiluminescence kit (Amersham Biosciences, London, UK).

Cell migration assay. MCF- 7 cells $\left(2 \times 10^{4}\right)$ were seeded in each well of a 24-well plate and incubated at $37^{\circ} \mathrm{C}$ with $5 \% \mathrm{CO}_{2}$ overnight. MCF-7 cells were pretreated with 25 , or 50 nM LYF-5, LYF-11, and LYF-17 for $2 \mathrm{~h}$. The cell layer was then scratched using a pipette tip and washed to remove debris and follow by fresh medium containing $0.5 \%$ serum with different concentrations of LYF-5, LYF-11 and LYF-17. Cells were then incubated with $50 \mathrm{ng} / \mathrm{ml}$ of IL-6 for $24 \mathrm{~h}$. IL-6-induced cell migration was determined by measuring the wound closure. Representative photographs were taken at $\times 200$ magnification using a NIKON TE2000-U inverted microscope (Nikon, Tokyo, Japan).

Flow cytometric analysis. To examine whether MCF-7 cells displayed a change in the proportion of tumor-initiating cells. MCF-7 cells were treated with dimethyl sulfoxide (DMSO) as a control, or $10-50 \mu \mathrm{g} / \mathrm{ml}$ of IL- 6 for $24 \mathrm{~h}$ or $48 \mathrm{~h}$ and detached with trypsin, washed once in FACs buffer (PBS containing 1-2\% bovine serum albumin and $5 \mathrm{mM}$ EDTA), then stained with anti-CD24fluorescein isothiocyanate (Invitrogen, Carlsbad, CA, USA) and anti-CD44 (Invitrogen, Carlsbad, CA, USA) using $10 \mu \mathrm{l}$ of antibody per $10^{6}$ cells, and incubated at $4^{\circ} \mathrm{C}$ for $15 \mathrm{~min}$. Following incubation, cells were washed once with FACS buffer and evaluated with FACScan and Cell Quest software (Becton Dickinson, Mountain View, CA, USA).

Confocal microscopy assay. Cells were plated into Lab-Tek twochamber slides (Nunc, Thermo Fisher Scientific, Rochester, NY, USA) overnight. The next day, cells were $50-70 \%$ confluent, washed once with PBS, and fixed and permeabilized in cold $100 \%$ methanol at $-20^{\circ} \mathrm{C}$ for $20 \mathrm{~min}$. Chambers were given three 5-min washes in $0.1 \%$ Tween-20/PBS (PBST) and were then incubated in $3 \%$ bovine serum albumin/0.1\% Tween-20/PBS blocking buffer for $1 \mathrm{~h}$ at room temperature. After one PBST wash, chambers were incubated with E-cadherin antibody. Nuclear staining was performed with DAPI. Cells were imaged with Leica TCS SP2 Spectral Confocal System (Leica Microsystems, Wetzlar, Germany).

Transient transfections. MCF-7 cells were transiently transfected with FLAG (DYKDDDDK epitope)-tagged expression vectors encoding a dominant active STAT3 (CA-STAT3). The CA-STAT3 vector was a kind gift from Dr. Mien-Chie Hung (Houston, TX, USA). One day before transfection, cells were seeded in a six-well plate without antibiotics. For plasmid transfections, $2 \mu \mathrm{g}$ of plasmid DNA were premixed with lipofectamine 2000 (Invitrogen, Carlsbad, CA, USA) in Opti-MEM and added to wells for $6 \mathrm{~h}$. The cells were then harvested and the protein expression was detected by Western blotting.
In vivo studies. Female severe combined immunodeficient (SCID) mice (4-6 weeks of age) were purchased from National Animal Center (Taipei, Taiwan, ROC) and maintained in pressurized ventilated cage, according to the Institutional Animal Care and Use Committee (IACUC) standard protocols. MCF-7 cells in log-phase growth $\left(5 \times 10^{6}\right.$ cells) were inoculated subcutaneously into the right flank of the mice. Growth of tumors was supplemented with $0.72 \mathrm{mg}$ of 60 day-release estrogen pellets (Innovative Research of America, Sarasota, FL, USA) which were implanted subcutaneously on the back of the animals $24 \mathrm{~h}$ prior to cell inoculation. When tumors reached an approximate volume of $100 \mathrm{~mm}^{3}$, the mice were divided into four groups (6 mice per group). The mice were given dimethyl sulfoxide (DMSO) (control), or LYF-11 (10, 20, $40 \mathrm{mg} / \mathrm{kg}$, respectively) by i.p. injection five times/weekly for 3 consecutive weeks. Mice were weighed and tumors were measured using calipers every week. Tumor volumes were determined by measuring the length (1) and the width (w) and the volumes were calculated as $\mathrm{V}=l w^{2} / 2$.

Statistical analysis. One-way analysis of variance (ANOVA) was used for the comparison of more than two mean values. Results represent at least two to three independent experiments and are shown as averages $\pm \mathrm{SD}$. Results with a $p$-value of less than 0.05 were considered statistically significant.

\section{Results}

IL-6 induced MCF-7 cells to undergo EMT. We first determined the optimum concentrations required for IL-6 to initiate EMT in MCF-7 cells. Changes in cell morphology were assessed following treatment of MCF-7 cells with 10-50 ng/ml of IL-6 for 24 and $48 \mathrm{~h}$. MCF-7 cells underwent morphological changes on exposure to IL-6. MCF-7 cells cultured in the absence of IL-6 maintained a classic cobblestone epithelial morphology and growth pattern, but after stimulation with IL- 6 for 24 and $48 \mathrm{~h}$, the cells adopted a more fibroblast-like morphology and their cell-cell contact was reduced (Figure 2A). The expression of the epithelial phenotype marker, E-cadherin, and of the mesenchymal phenotype marker, vimentin, was also determined following treatment of MCF-7 cells with 10-50 ng/ml of IL-6 for $24 \mathrm{~h}$. IL-6 reduced E-cadherin expression in a dose-dependent manner. In parallel with the marked decrease in the epithelial marker E-cadherin, IL-6 induced expression of the mesenchymal marker vimentin in a dose-dependent manner (Figure 2B). To determine whether IL-6 exposure functionally enhanced the migratory capacity of MCF-7 cells, the wound closure was measured. Dotted lines in Figure $2 \mathrm{C}$ indicate the colony edges at initial time point $\mathrm{T} 0$. Compared to cells treated with DMSO (control), IL-6 significantly induced cell migration. These results indicate that IL-6 initiated EMT in human breast cancer cells.

IL-6 promoted tumor-initiating ability in MCF-7 cells. We next examined whether MCF-7 cell populations induced through EMT displayed an increase in the proportion of CD $24^{-} / \mathrm{CD} 44^{+}$cells, cells associated with tumor-initiating 
A

IL-6 ( $\mu \mathrm{g} / \mathrm{ml})$

$24 \mathrm{~h}$

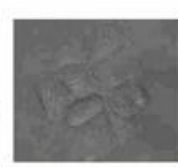

$48 \mathrm{~h}$

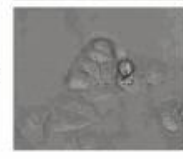

0
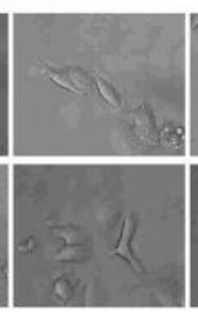

30

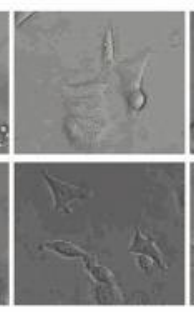

50

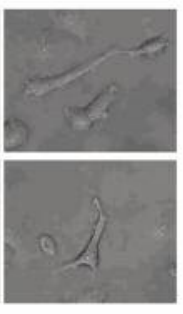

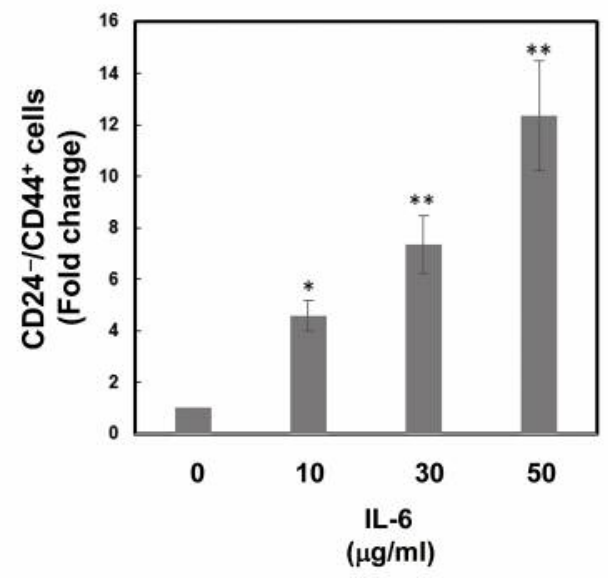
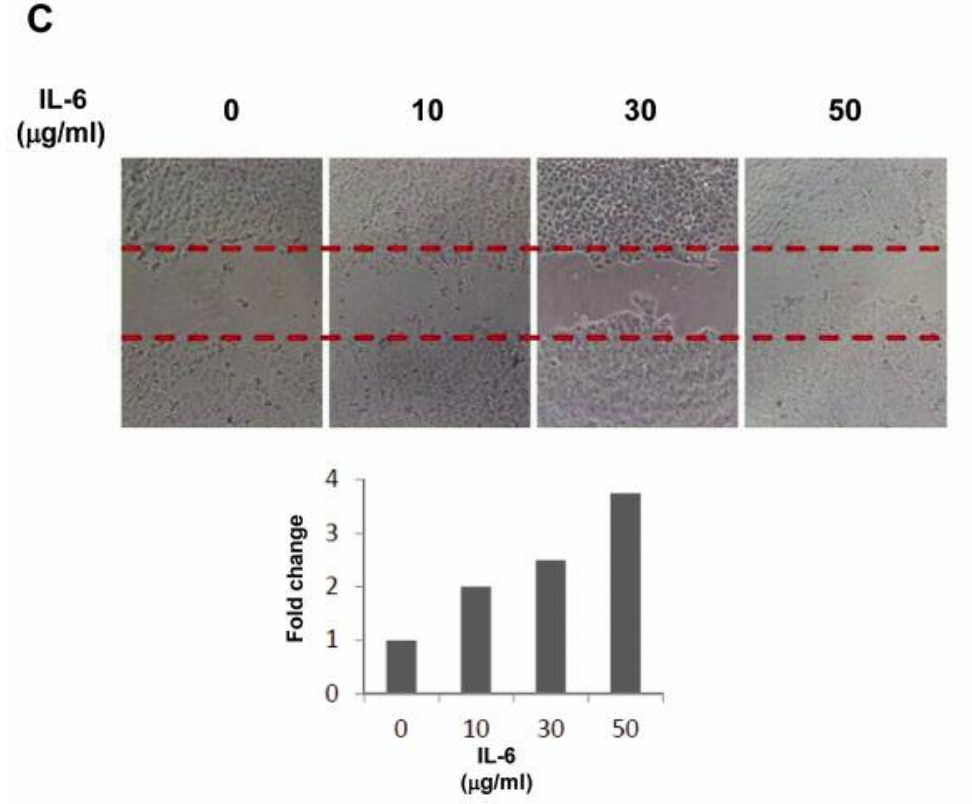

B

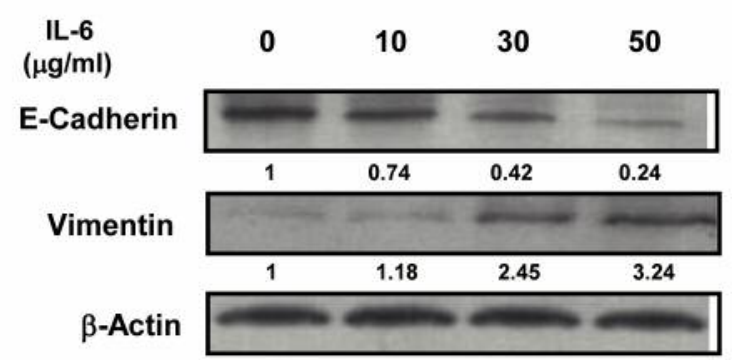

D

Figure 2. MCF-7 cells undergo epithelial-mesenchymal transition and tumor-initiating ability in response to interleukin-6 (IL-6). A: MCF-7 cells were treated with DMSO as a control, or 10-50 $\mathrm{\mu g} / \mathrm{ml}$ of IL-6 for $24 \mathrm{~h}$ or $48 \mathrm{~h}$. Phase-contrast microscopy images were taken using a $10^{3}$ objective. $B: M C F-7$ cells were treated with 10-50 $\mu \mathrm{g} / \mathrm{ml}$ of IL-6 for 24. The cells were then harvested and lysed for the detection of E-cadherin, vimentin, and $\beta$-actin. Western blot data presented are representative of those obtained in at least three separate experiments. Immunoblots were quantified, and expression relative to that of the control is indicated. C: For wound-healing assay, a confluent MCF-7 monolayer was incubated with 10-50 $\mu \mathrm{g} / \mathrm{ml}$ of IL-6 for $24 \mathrm{~h}$. Data are the mean $\pm S D(n=3)$. The closure distance of the control cells was set to 1. D: MCF-7 cells were treated with DMSO as a control, or 10-50 $\mu \mathrm{g} / \mathrm{ml}$ of IL-6 for $72 \mathrm{~h}$. Flow cytometric analysis of cell-surface markers, CD24-/CD44+, in the cells. Data are the mean $\pm S D(n=3)$. Value for cells treated with DMSO was set to 1. Significantly different at $* p<0.05 ; * *<<0.01$.

ability of breast cancer. We observed that IL-6 significantly increased the percentage of $\mathrm{CD} 24^{-} / \mathrm{CD} 44^{+}$cells (Figure 2D). These results indicate that MCF-7 cells that underwent EMT exhibited increased number of cells with a phenotype for tumor-initiating ability.

PTNO derivatives blocked IL-6-induced EMT of MCF-7 cells. The activation of IL-6 signaling significantly caused EMT in MCF-7 cells. To determine whether PTNO derivatives (Figure 1) inhibited IL-6-induced EMT, MCF-7 cells were pretreated with PTNOs prior to stimulation with IL-6. We examined the expression of EMT markers vimentin and Ecadherin in MCF-7 cells. Pretreatment with LYF-5, LYF-11 and LYF-17 significantly suppressed IL-6-induced upregulation of vimentin and down-regulation of E-cadherin in a dose-dependent manner (Figure 3A). To further confirm that LYF-5, LYF-11 and LYF-17 suppressed IL-6-induced upregulation of vimentin and down-regulation of E-cadherin, MCF-7 cells were imaged using confocal microscopy. As shown in Figure 3B, using antibodies against E-cadherin, 
A

$\begin{array}{lcccccccc}50 \mu \mathrm{g} / \mathrm{ml} \mathrm{IL-6} & - & + & + & + & + & + & + & + \\ \mathrm{LYF}-5(\mathrm{nM}) & - & - & 25 & 50 & - & - & - & - \\ \mathrm{LYF}-11(\mathrm{nM}) & - & - & - & - & 25 & 50 & - & - \\ \mathrm{LYF}-17(\mathrm{nM}) & - & - & - & - & - & - & 25 & 50\end{array}$
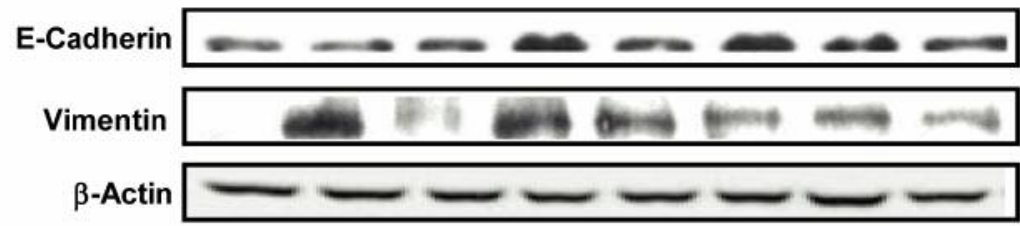

B

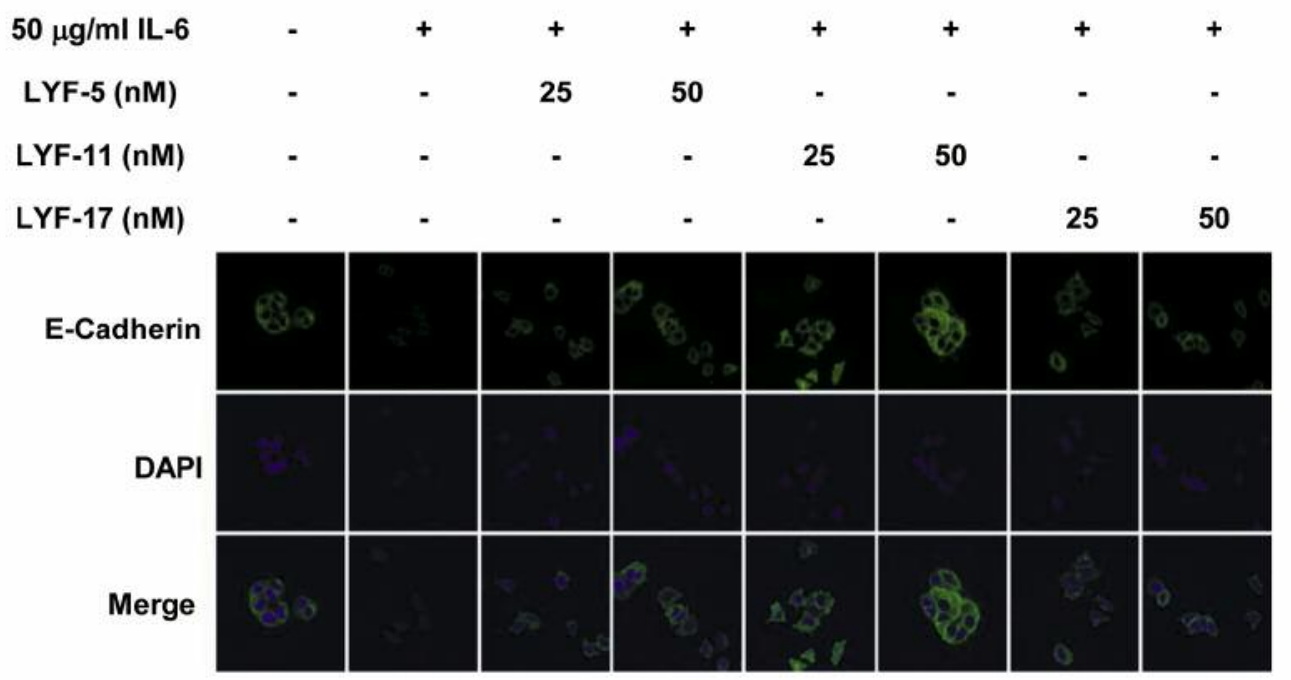

C

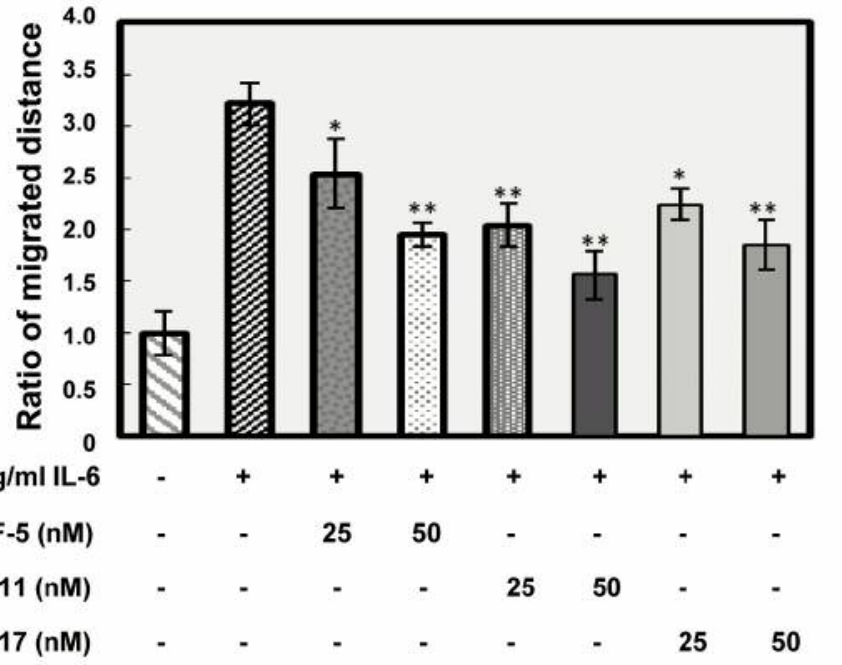

D

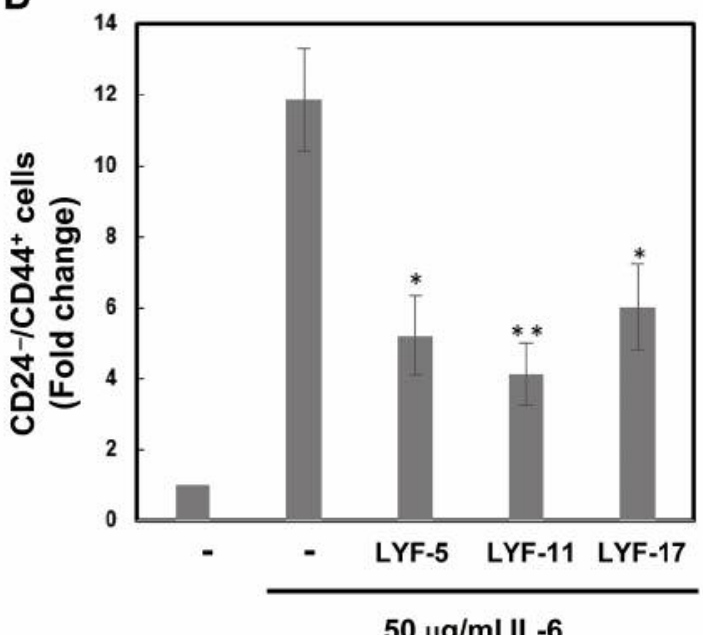

Figure 3. LYF-5, LYF-11, and LYF-17 block interleukin-6 (IL-6)-induced epithelial-mesenchymal transition and tumor-initiating ability in MCF-7 cells. MCF-7 cells were pretreated with dimethyl sulfoxide (DMSO; control) or increasing LYF-5, LYF-11, and LYF-17 concentrations (25, 50 nM) for $2 \mathrm{~h}$ prior to IL-6 stimulation $(50 \mu \mathrm{g} / \mathrm{ml})$ for $24 \mathrm{~h}$. A: The cells were then harvested and lysed for the detection of E-cadherin, vimentin, and $\beta$-actin. Western blot data presented are representative of those obtained in at least three separate experiments. B: Cells were fixed, permeabilized and stained with monoclonal antibody against E-cadherin (green) and (4',6-diamidino-2-phenylindole) (DAPI) (blue). Cells were analyzed by confocal microscopy. C: IL-6-induced cell migration was determined by measuring wound closure. The closure distance of the control cells was set to 1. Data are the mean $\pm S D(n=3)$. D: Flow cytometric analysis of cell-surface markers, CD24-/CD44+, in MCF-7 cells. Data are mean \pm SD ( $n=3)$. Data for the cells treated with DMSO were set to the value of 1 . Significantly different at $* p<0.05 ; * * p<0.01$. 
A

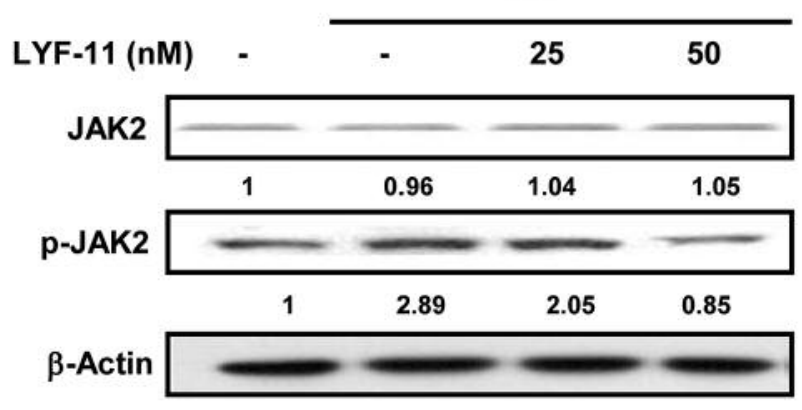

B

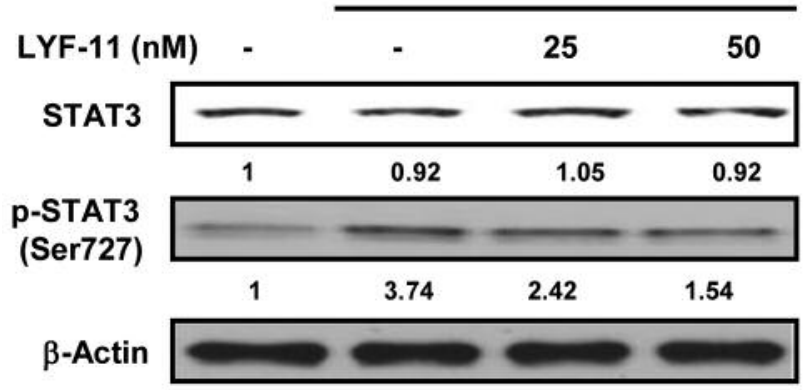

Figure 4. Effect of LYF-11 on interleukin-6 (IL-6)-induced Janus kinase $2(J A K 2) /$ signal transducer and activator of transcription 3 (STAT3) signaling pathway. MCF-7 cells were pre-treated with dimethyl sulfoxide (DMSO) (control) or increasing LYF-11 concentrations (25, $50 \mathrm{nM}$ ) for $2 \mathrm{~h}$ prior to IL-6 stimulation $(50 \mu \mathrm{g} / \mathrm{ml}$ ) for $30 \mathrm{~min}$. The cells were then harvested and lysed for the detection of JAK2, phospho-JAK2 (A), and STAT3, phospho-STAT3 (B), and $\beta$-actin. Western blot data presented are representative of those obtained in at least three separate experiments. Immunoblots were quantified, and expression relative to that of the control is indicated.

confocal microscopy indicated that IL-6 treatment alone resulted in up-regulation of vimentin and down-regulation of E-cadherin. Pretreatment with different concentrations of LYF-5, LYF-11 and LYF-17 for $2 \mathrm{~h}$ significantly suppressed the IL-6-induced down-regulation of E-cadherin in a dosedependent manner (Figure $3 \mathrm{~A}$ and $\mathrm{B}$ ).

PTNO derivatives blocked IL-6-induced cell migration. We further examined whether PTNO derivatives also affected IL-6-induced cell migration. Compared to cells treated with DMSO (control), IL-6 significantly induced cell migration. Notably, the IL-6-induced cell migration was abrogated in the presence of LYF-5, LYF-11 and LYF-17 (Figure 3C).

Effect of PTNO derivatives on IL-6-promoted tumor-initiating ability in MCF-7 cells. Since under IL-6 treatment MCF-7 cells with tumor-initiating phenotype increased, we next determined whether pretreatment with PTNO derivatives would suppress IL-6-induced tumor-initiating ability. We observed that pretreatment with LYF-5, LYF-11 and LYF-17 significantly increased the percentage of CD24/CD $44^{+}$cells (Figure 3D). Our data showed that PTNO derivatives inhibited IL-6-mediated EMT, cell migration, and development of tumor-initiating phenotype in MCF-7 cells. Interestingly, LYF-11 had the most potent inhibitory activity among these PTNO derivatives, therefore, we selected LYF-11 for further experiments.

LYF-11 inhibited IL-6-induced JAK2/STAT3 signaling pathway in MCF-7 cells. The JAK2/STAT3 pathway is involved in the IL-6-mediated regulation of tumor progression. We next investigated whether LYF-11 could inhibit this activity of IL6. Interestingly, $50 \mathrm{ng} / \mathrm{ml}$ of IL-6 induced the phosphorylation of JAK2 and STAT3 within 30 min of stimulation but with no effect on total expression of JAK2 and STAT3 (Figure 4A and B). Pretreatment with LYF-11 for $2 \mathrm{~h}$ significantly suppressed the IL-6-induced phosphorylation of JAK2 (Figure 4A) and STAT3 (Figure 4B).

LYF-11 inhibited IL-6-induced EMT via the inhibition of JAK2/STAT3 signaling pathway in MCF-7 cells. To further confirm whether JAK2/STAT3 signaling pathway is involved in LYF-11-inhibited IL-6-mediated EMT, EGCG, a potent and specific inhibitor of STAT3, was used to inhibit IL-6-induced phosphorylation of STAT3 in MCF-7 cells. Western blot analysis revealed that IL-6-induced phosphorylation of STAT3, and up-regulation of vimentin were significantly inhibited by pretreatment with $40 \mu \mathrm{M}$ EGCG (Figure 5A). We also tested for the effect of co-pretreatment with EGCG $(40 \mu \mathrm{M})$ and LYF-11 (50 nM) on phosphorylated STAT3, and vimentin protein levels after IL-6 treatment. In the co-presence of EGCG (40 $\mu \mathrm{M})$ and LYF-11 (50 nM), IL-6-induced phosphorylation of STAT3, and up-regulation of vimentin were more potent than pretreatment with EGCG or LYF-11 alone (Figure 5A). Under the resting state, STAT3 is unphosphorylated and retained in the cytoplasm. Upon activation, STAT3 is phosphorylated and undergoes dimerization with STAT3, thus permitting its translocation into the nucleus. Therefore, we also confirmed the subcellular location of STAT3 in MCF-7 cells under LYF-11 treatment. MCF-7 cells were grown on a glass slide and pretreated with LYF-11 for $2 \mathrm{~h}$ prior to stimulation with IL-6 $(50 \mathrm{ng} / \mathrm{ml})$ for $24 \mathrm{~h}$ followed by immunostaining with phospho-STAT3 antibody. Figure 5B clearly demonstrates that after treatment with IL-6, phospho-STAT3 signals were mainly present in the nuclei, however, these shifted to the cytoplasm of MCF-7 cells by LYF-11 treatment. We also tested for the effect of co-pretreatment with EGCG $(40 \mu \mathrm{M})$ and LYF-11 $(50 \mathrm{nM})$. In the co-presence of EGCG $(40 \mu \mathrm{M})$ and LYF-11 $(50 \mathrm{nM})$, the inhibition of nuclear location of phosphoSTAT3 was more potent than pretreatment with EGCG or LYF- 
A

\begin{tabular}{|c|c|c|c|c|c|}
\hline \multirow[b]{2}{*}{ LYF-11 (nM) } & & \\
\hline & & - & 50 & - & 50 \\
\hline EGCG $(\mu \mathrm{M})$ & - & - & - & 40 & 40 \\
\hline \multirow{2}{*}{$\begin{array}{r}\text { p-STAT3 } \\
\text { (Ser727) }\end{array}$} & - & - & - & - & - \\
\hline & 1 & 2.74 & 1.12 & 1.54 & 0.22 \\
\hline \multirow[t]{2}{*}{ STAT3 } & $=-1$ & $=$ & $=$ & $=1$ & 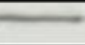 \\
\hline & 1 & 1.11 & 0.97 & 0.96 & 0.92 \\
\hline \multirow[t]{2}{*}{ Vimentin } & $=$ & 5 & 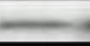 & 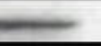 & \\
\hline & 1 & 3.24 & $0 . .92$ & 1.64 & 0.12 \\
\hline$\beta$-Actin & & & & & \\
\hline
\end{tabular}

C

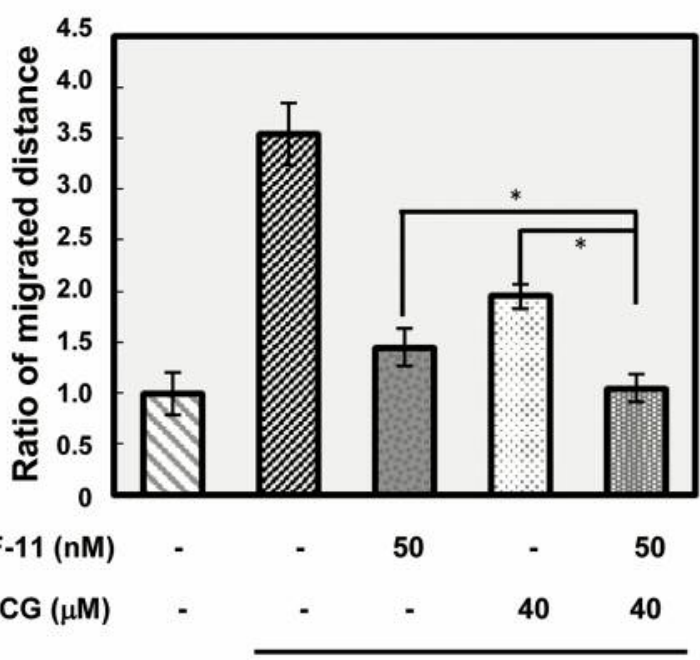

$50 \mu \mathrm{g} / \mathrm{ml} \mathrm{IL-6}$

B

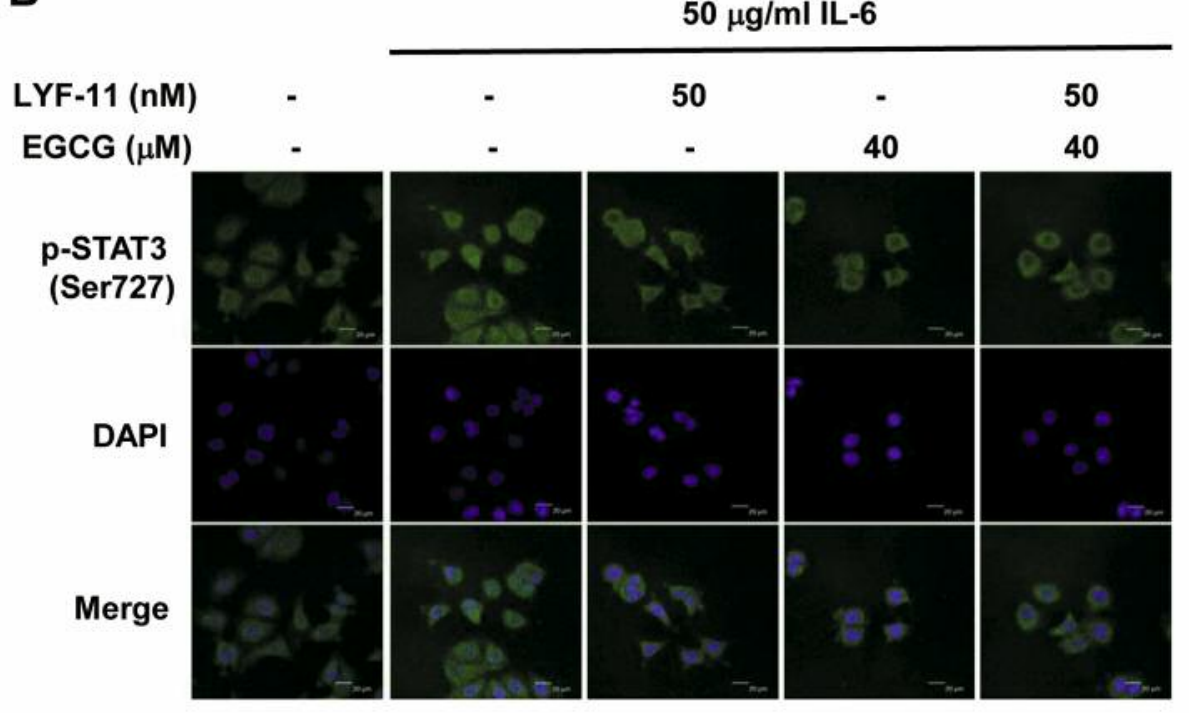

Figure 5. LYF-11 blocks interleukin-6 (IL-6)-induced epithelial-mesenchymal transition via the Janus kinase 2 (JAK2)/signal transducer and activator of transcription 3 (STAT3) signaling pathway in MCF-7 cells. A: MCF-7 cells were pretreated with $40 \mu M$ (-)-epigallocatechin-3-gallate

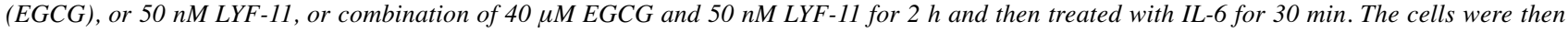
harvested and lysed for the detection of phospho-STAT3, STAT3, vimentin and $\beta$-actin. Western blot data presented are representative of those obtained in at least three separate experiments. Immunoblots were quantified, and expression relative to that of the control is indicated. B: MCF-7 cells were pretreated with $40 \mu M$ EGCG, or $50 \mathrm{nM} L Y F-11$, or combination of $40 \mu M$ EGCG and $50 \mathrm{nM} L Y F-11$ for $2 \mathrm{~h}$ and then treated with IL-6 for $30 \mathrm{~min}$. Cells were fixed, permeabilized and stained with monoclonal antibody to phosphoSTAT3 (green) and (4',6-diamidino-2-phenylindole) (DAPI) (blue). Cells were analyzed by confocal microscopy. C: For wound-healing assay, MCF-7 cells were pretreated with $40 \mu M$ EGCG, or $50 \mathrm{nM}$ LYF-11, or combination of $40 \mu \mathrm{M} \mathrm{EGCG}$ and $50 \mathrm{nM}$ LYF-11 for $2 \mathrm{~h}$ and then treated with IL-6 for $24 \mathrm{~h}$. Cell motility was determined by measuring the closure of wound. Data are the mean $\pm S D(n=3)$. Combination of LYF-11 and EGCG significantly inhibited IL-6-induced cell motility compared with LYF-11 or EGCG alone. Significantly different at * $p<0.05$.

11 alone (Figure 5B). These results indicate that LYF-11 has the ability to suppress, not only phosphorylation of STAT3, but also its translocation to the nucleus. To confirm whether STAT3 is involved in LYF-11-inhibition of IL-6-mediated cell migration, cell migration was determined in a wound-closure assay. IL-6-induced cell migration was significantly inhibited by pretreatment with $50 \mathrm{nM}$ LYF-11. In the co-presence of EGCG $(40 \mu \mathrm{M})$ and LYF-11 $(50 \mathrm{nM})$, IL-6-induced cell migration was more potent than that under pretreatment with EGCG and LYF-11 alone (Figure 5C). 


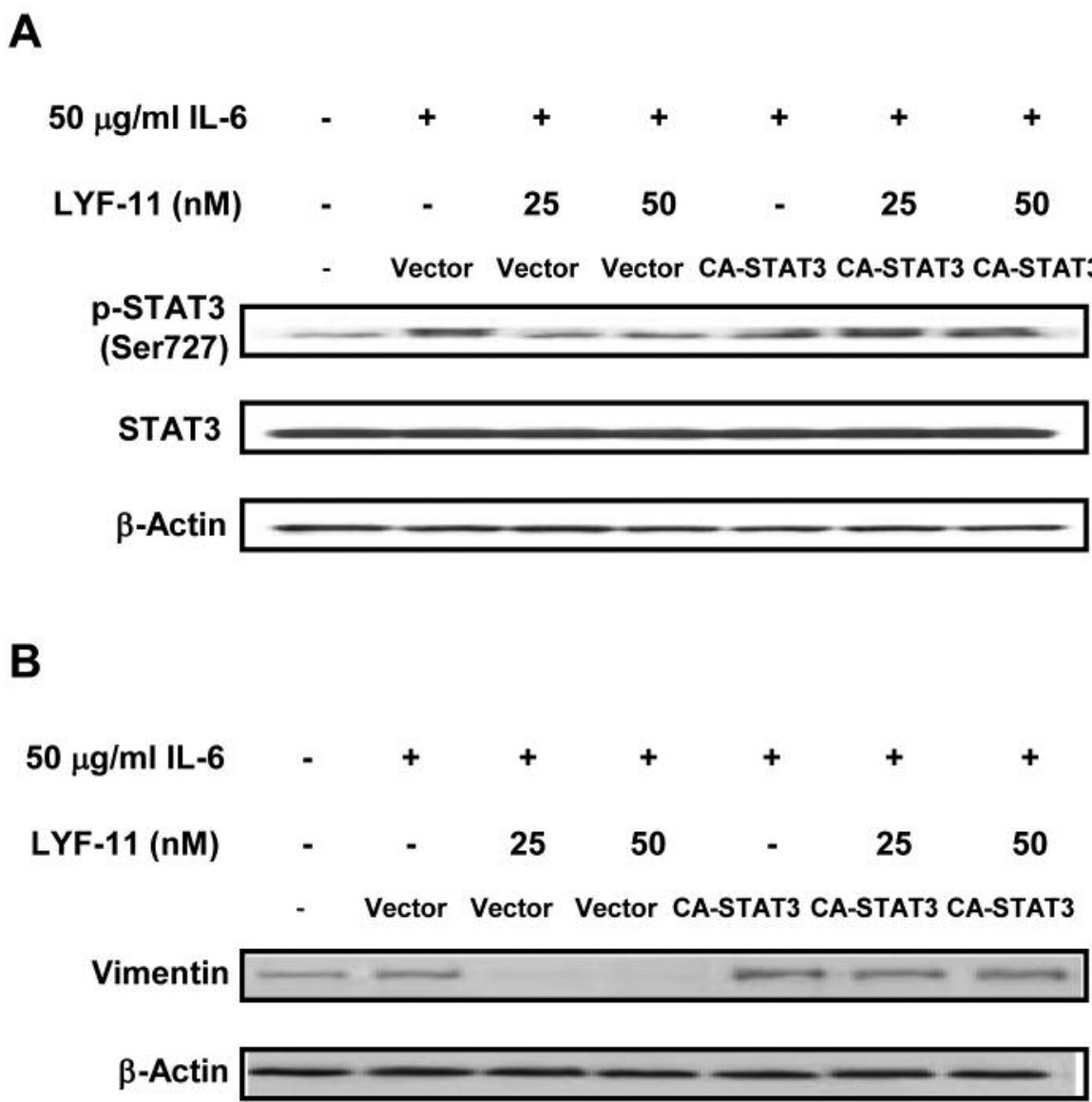

Figure 6. Signal transducer and activator of transcription 3 (STAT3) overexpression restored interleukin-6 (IL-6)-induced epithelial-mesenchymal transition inhibited by LYF-11. A: MCF-7 cells were transfected with dominant active STAT3 (CA-STAT3) or empty vector. Twenty-four hours after transfection, cells were pretreated with increasing LYF-11 concentrations $(25,50 \mathrm{nM})$ for $2 \mathrm{~h}$ prior to IL-6 stimulation $(50 \mu \mathrm{g} / \mathrm{ml})$ for $30 \mathrm{~min}$. The cells were then harvested and lysed for the detection of phospho-STAT3, STAT3, and $\beta$-actin. B: MCF-7 cells were transfected with CA-STAT3 or empty vector. Twenty-four hours after transfection, cells were pretreated with increasing LYF-11 concentrations (25, $50 \mathrm{nM})$ for $2 \mathrm{~h}$ prior to IL-6 stimulation $(50 \mu \mathrm{g} / \mathrm{ml})$ for $24 \mathrm{~h}$. The cells were then harvested and lysed for the detection of vimentin, and $\beta$-actin. Western blot data presented are representative of those obtained in at least three separate experiments.

STAT3 overexpression restored LYF-11 inhibition of IL-6induced EMT. If STAT3 is a critical target of LYF-11, overexpression of STAT3 should attenuate LYF-11 inhibition of IL-6-induced EMT. To test this hypothesis, we carried out a STAT3-overexpression experiment using cDNA of CASTAT3 (a constitutively active mutant dimerized by cysteinecysteine bridges instead of pTyr-SH2 interaction). Despite LYF-11 treatment, STAT3-overexpressing MCF-7 cells had a clearly detectable level of Ser727-phosphorylated STAT3 (Figure 6A). Our study found that the STAT3 overexpression restored LYF-11 inhibition of IL-6-induced EMT (Figure $6 \mathrm{~B})$. These data suggest that LYF-11 might target, at least in part, STAT3 in MCF-7 cells.

In vivo antitumor activity of LYF-11. To investigate the in vivo antitumor activity of LYF-11, we carried out experiments with MCF-7 cell xenografts in SCID mice. LYF-11 induced a dose-dependent inhibition of MCF-7 tumor growth (Figure 7A). LYF-11 showed significant antitumor activity, moreover, body weights were not significantly affected by LYF-11 (Figure 7B).

\section{Discussion}

Herein, in agreement with a previous report (15), we show that IL-6 promoted an EMT phenotype in human breast cancer cells. We found that IL- 6 caused MCF-7 cells to lose their polygonal appearance and cell-cell contacts. IL-6 induced MCF-7 breast adenocarcinoma cells to exhibit an EMT phenotype characterized by impaired E-cadherin expression and induction of vimentin. Our data also show that IL-6 significantly increased migration and cells with tumor- 


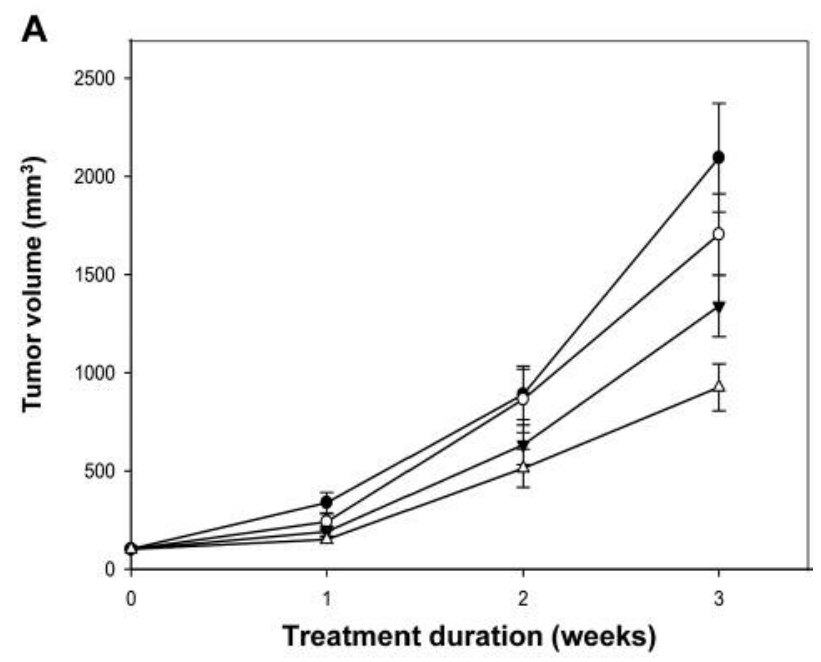

B
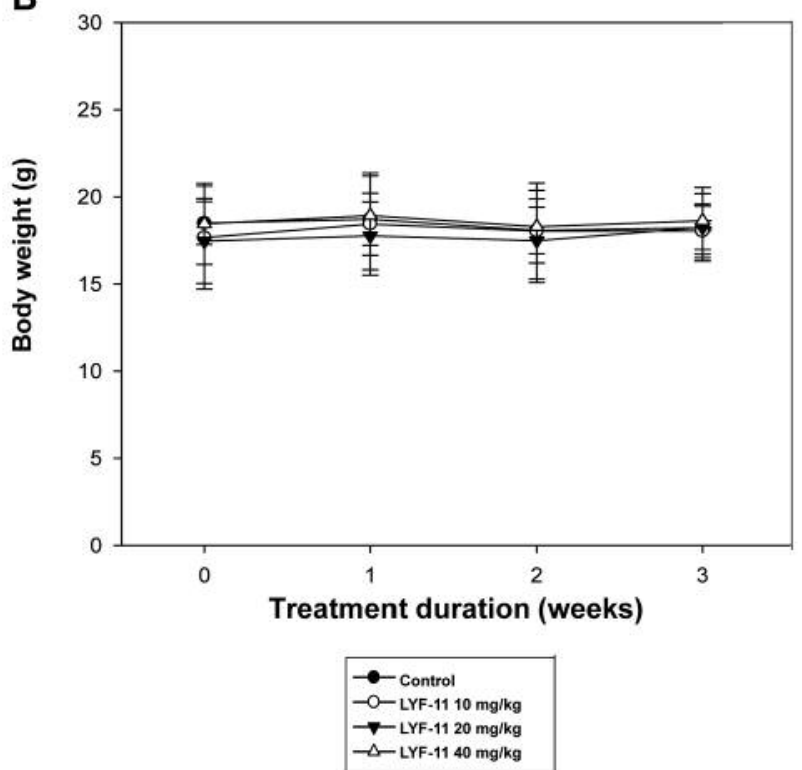

Figure 7. Effect of LYF-11 on antitumor activity. MCF-7 cells were used to establish xenografts in male SCID mice. Animals (six mice/group) were given dimethyl sulfoxide (DMSO) (control), or LYF-11 (10, 20, $40 \mathrm{mg} / \mathrm{kg}$, respectively) by i.p. injection five times/weekly. Tumor volume (A) and body weight of mice are shown.

initiating phenotype when compared with MCF-7 control cells. The IL-6/STAT3 signaling pathway is one of various inducers of EMT. Our study investigated the effects of a novel PTNO derivative, LYF-11, showing it suppressed EMT by regulating the IL-6/STAT3 signaling pathway. Collectively, our study provides experimental evidence for the potential use of LYF-11 in the treatment of breast tumor metastasis.

Inflammation and the immune response have long been viewed as a delicate balance that has the ability to promote migration, invasion and metastasis of malignant cells (28).
Inflammatory cells secrete various inflammatory factors, such as TNF- $\alpha$, IL- $1 \beta$ and IL- 6 to activate the major inflammatory signaling pathways, facilitating both tumor development and metastatic progression. Previous studies found that IL-6 is a potent inducer of EMT in breast cancer cells with an epithelial phenotype (29). Human breast cancer cell lines (30) and primary human breast tumor cells (31) are capable of producing autocrine IL-6, suggesting tumor cells as a source of aberrantly increased tumor and serum IL-6. In our study, we demonstrate that IL-6 was able to drive EMT and promote human breast MCF-7 cells with a tumor-initiating phenotype. Taken together, these findings suggested a role for IL-6 in the progression of human breast tumor.

Disseminated breast cancer cells that have presumably undergone EMT may exhibit a tumor-initiating phenotype of CD24-/CD44 ${ }^{+}$cells (32). Various inflammatory factors are reported to induce EMT and tumor-initiating characteristics (33). IL-6 is able to initiate EMT (15) and expand the tumorinitiating population (14) of human breast cancer cells. Moreover, addition of recombinant IL-6 to parental cells led to the expression of EMT-associated genes and expansion of tumor-initiating cells (34). Our results confirmed that breast cancer cells up-regulate IL-6 production, with subsequent induction of EMT and tumor-initiating properties.

Our previous study showed that PTNO derivatives possess strong inhibitory effects against several kinds of tumor cell lines, such as leukemia, colon, CNS, melanoma, ovarian, renal, prostate, breast, and small cell lung cancer cell lines, with half maximal inhibitory concentration $\left(\mathrm{IC}_{50}\right)$ values of low micromolar to nanomolar concentration range (35). It is notable that LYF-5, LYF-11, and LYF-17 had highly selective effects on several cell lines, such as leukemia, breast, and non-small lung cancer cells. In this study, we tested whether LYF-5, LYF-11, and LYF-17 inhibited IL-6induced EMT. Our study found that pretreatment with LYF5, LYF-11 and LYF-17 significantly suppressed the IL-6induced up-regulation of vimentin. LYF-11 showed a stronger inhibitory effect than the other PTNO derivatives on IL-6-induced EMT and expansion of MCF-7 cells with tumor-initiating phenotype. Moreover, we demonstrated that LYF-11 inhibited MCF-7 cell migration induced by IL-6. This indicates that LYF-11 has potential anti-migratory activity during EMT in an inflammatory microenvironment.

IL-6/IL-6R acts mainly through the JAK/STAT3 signaling pathway. Previous studies found that IL-6 stimulated the activation of JAK/STAT3 signaling pathway in cancer cells, and played an important role in cell proliferation, apoptosis, angiogenesis, and metastasis $(36,37)$. Moreover, the activation of STAT3 in tumor cells promoted tumor growth by increasing the capacity of tumors to evade the immune system $(38,39)$. EMT in tubular epithelial cells was shown to be induced by the JAK/STAT3 pathway (40). Recently, it was reported that the activation of STAT3 pathway facilitated 
SNAIL and TWIST stabilization in human breast cancer cells (41). Moreover, gastrin induced EMT in colon cancer through JAK/STAT3 pathway (42). Additionally, STAT3 is involved in EMT, and STAT3 phosphorylation is significantly correlated with tumor, lymph node, and metastasis stages in ovarian cancer (43). In this study, we found that LYF-11 inhibited STAT3 activation by IL-6, prevented phosphoSTAT3 dimers from translocating to the nucleus and inhibited EMT. Overexpression of STAT3 by transfecting CA-STAT3 plasmid correspondingly reversed ILY-11 inhibition of IL-6induced EMT. These results demonstrate that the STAT3 signaling pathway regulated the process of EMT.

In summary, we found that IL-6 induced an EMT phenotype and tumor-initiating ability in MCF-7 cells. LYF11 can inhibit IL-6 induced EMT by blocking JAK2/STAT3 phosphorylation, suggesting a potential clinical use of LYF11 in the treatment of human breast cancer.

\section{Acknowledgements}

This study was supported by the Changhua Christian Hospital grant.

\section{References}

1 Hutchinson L: Breast cancer: challenges, controversies, breakthroughs. Nat Rev Clin Oncol 7: 669-670, 2010.

2 Dontu G, Liu S and Wicha MS: Stem cells in mammary development and carcinogenesis: implications for prevention and treatment. Stem Cell Rev 1: 207-213, 2005.

3 Fillmore $\mathrm{C}$ and Kuperwasser C: Human breast cancer stem cell markers CD44 and CD24: enriching for cells with functional properties in mice or in man? Breast Cancer Res 9: 303, 2007.

4 Reya T, Morrison SJ, Clarke MF and Weissman IL: Stem cells, cancer and cancer stem cells. Nature 414: 105-111, 2001.

5 Sheridan C, Kishimoto H, Fuchs RK, Mehrotra S, BhatNakshatri P, Turner CH, Goulet R Jr., Badve S and Nakshatri H: CD44+/CD24- breast cancer cells exhibit enhanced invasive properties: an early step necessary for metastasis. Breast Cancer Res 8: R59, 2006.

6 Chiotaki R, Polioudaki H and Theodoropoulos PA: Cancer stem cells in solid and liquid tissues of breast cancer patients: characterization and therapeutic perspectives. Curr Cancer Drug Targets 15: 256-269, 2015.

7 Thiery JP and Sleeman JP: Complex networks orchestrate epithelial-mesenchymal transitions. Nat Rev Mol Cell Biol 7: 131-142, 2006.

8 Cowin P, Rowlands TM and Hatsell SJ: Cadherins and catenins in breast cancer. Curr Opin Cell Biol 17: 499-508, 2005.

9 Mantovani A, Allavena P, Sica A and Balkwill F: Cancer-related inflammation. Nature 454: 436-444, 2008.

10 DeMichele A, Martin AM, Mick R, Gor P, Wray L, Klein-Cabral M, Athanasiadis G, Colligan T, Stadtmauer E and Weber B: Interleukin-6-174G $\rightarrow \mathrm{C}$ polymorphism is associated with improved outcome in high-risk breast cancer. Cancer Res 63: 8051-8056, 2003.

11 Kozlowski L, Zakrzewska I, Tokajuk P and Wojtukiewicz MZ: Concentration of interleukin-6 (IL-6), interleukin-8 (IL-8) and interleukin-10 (IL-10) in blood serum of breast cancer patients. Rocz Akad Med Bialymst 48: 82-84, 2003.

12 Salgado R, Junius S, Benoy I, Van Dam P, Vermeulen P, Van Marck E, Huget $P$ and Dirix LY: Circulating interleukin-6 predicts survival in patients with metastatic breast cancer. Int $\mathrm{J}$ Cancer 103: 642-646, 2003.

13 Korkaya H, Kim GI, Davis A, Malik F, Henry NL, Ithimakin S, Quraishi AA, Tawakkol N, D’Angelo R, Paulson AK, Chung S, Luther T, Paholak HJ, Liu S, Hassan KA, Zen Q, Clouthier SG and Wicha MS: Activation of an IL6 inflammatory loop mediates trastuzumab resistance in HER2+ breast cancer by expanding the cancer stem cell population. Mol Cell 47: 570$584,2012$.

14 Xie G, Yao Q, Liu Y, Du S, Liu A, Guo Z, Sun A, Ruan J, Chen L, Ye C and Yuan Y: IL-6-induced epithelial-mesenchymal transition promotes the generation of breast cancer stem-like cells analogous to mammosphere cultures. Int J Oncol 40: 11711179, 2012.

15 Sullivan NJ, Sasser AK, Axel AE, Vesuna F, Raman V, Ramirez $\mathrm{N}$, Oberyszyn TM and Hall BM: Interleukin-6 induces an epithelial-mesenchymal transition phenotype in human breast cancer cells. Oncogene 28: 2940-2947, 2009.

16 Heinrich PC, Behrmann I, Muller-Newen G, Schaper F and Graeve L: Interleukin-6-type cytokine signalling through the GP130/JAK/STAT pathway. Biochem J 334: 297-314, 1998.

17 Huang C, Yang G, Jiang T, Zhu G, Li H and Qiu Z: The effects and mechanisms of blockage of STAT3 signaling pathway on IL6 inducing EMT in human pancreatic cancer cells in vitro. Neoplasma 58: 396-405, 2011.

18 Yadav A, Kumar B, Datta J, Teknos TN and Kumar P: IL-6 promotes head and neck tumor metastasis by inducing epithelial-mesenchymal transition via the JAK-STAT3-SNAIL signaling pathway. Mol Cancer Res 9: 1658-1667, 2011.

19 Kuo SC, Lee HZ, Juang JP, Lin YT, Wu TS, Chang JJ, Lednicer D, Paull KD, Lin CM and Hamel E: Synthesis and cytotoxicity of 1,6,7,8-substituted 2-(40-substituted phenyl)-4-quinolones and related compounds: identification as antimitotic agents interacting with tubulin. J Med Chem 36: 1146-1156, 1993.

$20 \mathrm{Li} \mathrm{L}$, Wang HK, Kuo SC, Wu TS, Lednicer D, Lin CM, Hamel $\mathrm{E}$ and Lee KH: Antitumor agents. 150. 2', 3', 4', 5', 5,6,7substituted 2-phenyl-4-quinolones and related compounds: their synthesis, cytotoxicity and inhibition of tubulin polymerization. J Med Chem 37: 1126-1135, 1994.

21 Chen YC, Lu PH, Pan SL, Teng CM, Kuo SC, Lin TP, Ho YF, Huang YC and Guh JH: Quinolone analogue inhibits tubulin polymerization and induces apoptosis via CDK1-involved signaling pathways. Biochem Pharmacol 74: 10-19, 2007.

22 Lin YC, Hou SC, Hung CM, Lin JN, Chen WC, Ho CT, Kuo SC and Way TD: Inhibition of the insulin-like growth factor 1 receptor by CHM-1 blocks proliferation of glioblastoma multiforme cells. Chem Biol Interact 231: 119-126, 2015.

23 Lee JC, Chou LC, Huang CH, Chung JG, Huang LJ, Lee KH, Hung MC, Way TD and Kuo SC: CHM-1 induces apoptosis via p38-mediated up-regulation of DR5 expression in human ovarian cancer SKOV3 cells. Eur J Pharmacol 670: 96-104, 2011.

24 Chen HY, Lu HF, Yang JS, Kuo SC, Lo C, Yang MD, Chiu TH, Chueh FS, Ho HC, Ko YC and Chung JG: The novel quinolone CHM-1 induces DNA damage and inhibits DNA repair gene expressions in a human osterogenic sarcoma cell line. Anticancer Res 30: 4187-4192, 2010. 
25 Lai TY, Yang JS, Wu PP, Huang WW, Kuo SC, Ma CY, Gibson Wood $\mathrm{W}$ and Chung JG: The quinolone derivative CHM-1 inhibits murine WEHI-3 leukemia in BALB/c mice in vivo. Leuk Lymphoma 51: 2098-2102, 2010.

26 Wang SW, Pan SL, Huang YC, Guh JH, Chiang PC, Huang DY, Kuo SC, Lee KH and Teng CM: CHM-1, a novel synthetic quinolone with potent and selective antimitotic antitumor activity against human hepatocellular carcinoma in vitro and in vivo. Mol Cancer Ther 7: 350-360, 2008.

27 Liu YJ, Lin YC, Lee JC, Kuo SC, Ho CT, Huang LJ, Kuo DH and Way TD: CCT327 enhances TRAIL-induced apoptosis through the induction of death receptors and dow-nregulation of cell survival proteins in TRAIL-resistant human leukemia cells Oncol Rep 32: 1257-1264, 2014.

28 Aggarwal BB, Shishodia S, Sandur SK, Pandey MK and Sethi $\mathrm{G}$ : Inflammation and cancer: how hot is the link? Biochem Pharmacol 72: 1605-1621, 2006.

29 Sullivan NJ, Sasser AK, Axel AE, Vesuna F, Raman V, Ramirez $\mathrm{N}$, Oberyszyn TM and Hall BM: Interleukin-6 induces an epithelial-mesenchymal transition phenotype in human breast cancer cells. Oncogene 28: 2940-2947, 2009.

30 Sasser AK, Sullivan NJ, Studebaker AW, Hendey LF, Axel AE and Hall BM: Interleukin- 6 is a potent growth factor for ERalpha positive human breast cancer. FASEB J 21: 3763-3770, 2007.

31 Sansone P, Storci G, Tavolari S, Guarnieri T, Giovannini C, Taffurelli M, Ceccarelli C, Santini D, Paterini P, Marcu KB, Chieco $\mathrm{P}$ and Bonafè $\mathrm{M}$ : IL-6 triggers malignant features in mammospheres from human ductal breast carcinoma and normal mammary gland. J Clin Invest 117: 3988-4002, 2007.

32 Al-Hajj M, Wicha MS, Benito-Hernandez A, Morrison SJ and Clarke MF: Prospective identification of tumorigenic breast cancer cells. Proc Natl Acad Sci USA 100: 3983-3988, 2003.

33 Smith HA and Kang Y: The metastasis-promoting roles of tumor-associated immune cells. J Mol Med 91: 411-429, 2013.

34 Yang L, Han S and Sun Y: An IL6-STAT3 loop mediates resistance to PI3K inhibitors by inducing epithelialmesenchymal transition and cancer stem cell expansion in human breast cancer cells. Biochem Biophys Res Commun 453: 582-587, 2014

35 Chen K, Kuo SC, Hsieh MC, Mauger A, Lin CM, Hamel E and Lee KH: Antitumor agents. 174. 2',3',4',5,6,7-Substituted 2phenyl-1,8-naphthyridin-4-ones: their synthesis, cytotoxicity and inhibition of tubulin polymerization. J Med Chem 40: 2266$2275,1997$.
36 Hodge DR, Hurt EM and Farrar WL: The role of IL-6 and STAT3 in inflammation and cancer. Eur J Cancer 41: 2502-2512, 2005.

37 Heinrich PC, Behrmann I, Muller-Newen G, Schaper F and Graeve L: Interleukin-6-type cytokine signalling through the gp130/Jak/STAT pathway. Biochem J 334: 297-314, 1998.

38 See AP, Han JE, Phallen J, Binder Z, Gallia G, Pan F, Jinasena D, Jackson C, Belcaid Z, Jeong SJ, Gottschalk C, Zeng J, Ruzevick J, Nicholas S, Kim Y, Albesiano E, Pardoll DM and Lim M: The role of STAT3 activation in modulating the immune microenvironment of GBM. J Neurooncol 110: 359-368, 2012.

39 Kida H, Ihara S and Kumanogoh A: Involvement of STAT3 in immune evasion during lung tumorigenesis. Oncoimmunology 2: e22653, 2013.

40 Nightingale J1, Patel S, Suzuki N, Buxton R, Takagi KI, Suzuki J, Sumi Y, Imaizumi A, Mason RM and Zhang Z: Oncostatin M, a cytokine released by activated mononuclear cells, induces epithelial cell-myofibroblast transdifferentiation via JAK/STAT pathway activation. J Am Soc Nephrol 15: 21-32, 2004.

$41 \mathrm{Wu}$ Y, Deng J, Rychahou PG, Qiu S, Evers BM and Zhou BP: Stabilization of snail by NF-kappaB is required for inflammation-induced cell migration and invasion. Cancer Cell 15: 416-428, 2009

42 Ferrand A, Kowalski-Chauvel A, Bertrand C, Pradayrol L, Fourmy D, Dufresne $M$ and Seva C: Involvement of JAK2 upstream of the PI3-kinase in celI-cell adhesion regulation by gastrin. Exp Cell Res 301: 128-138, 2004.

43 Colomiere M, Ward AC, Riley C, Trenerry MK, Cameron-Smith D, Findlay J, Ackland L and Ahmed N: Cross talk of signals between EGFR and IL-6R through JAK2/STAT3 mediate epithelial-mesenchymal transition in ovarian carcinomas. Br J Cancer 100: 134-144, 2009.
Received January 8, 2018

Revised January 29, 2018

Accepted February 9, 2018 